\title{
Meteorological Indices Approach for Prediction of Thunderstorm Probability at Two Coastal Sites in Egypt
}

\author{
O. S. Ahmed, M. A. Sadek \\ Nuclear and Radiological Regulatory Authority, Naser City, Egypt \\ Email: olfatsaad2005@yahoo.com
}

Received 5 May 2015; accepted 15 June 2015; published 18 June 2015

Copyright (C) 2015 by authors and Scientific Research Publishing Inc.

This work is licensed under the Creative Commons Attribution International License (CC BY). http://creativecommons.org/licenses/by/4.0/

c) (†) Open Access

\begin{abstract}
Siting of hazardous facilities such as Nuclear power plants requires the investigation of the meteorological and climatologically of the site region to derive extreme values of the meteorological variables to be considered in the design for safety purposes. Not only normally occurring meteorological conditions but also extremely rare events are considered. The present work is devoted to predict the likelihood of the Thunderstorm which is one of the rare events of concern for plant safety. Four atmospheric stability indices such as K-indices, the Showalter-indices, total totalsindices and the SWEAT-indices have been used for that. These function of meteorological parameters such as temperature, wind speed, wind direction and dew point at levels of pressure at 500, 700 and 850 hpa to predict the thunderstorm probability. Two Egyptian coastal sities have been chosen for the investigation, one on the Mediterranean Sea and the other on Red Sea; El Sallum and Sharm El Sheikh. The results show that the probability of thunderstorm occurred within the months January and February during 1989-2003, where the maximum value of SI, K, TT and SWEAT indices at January \& February months equals $29.31 \& 28.20,18.4 \& 20.3 \& 48.1 \& 49$ and $238.01 \& 350.6$ for Sallum city respectively, and equals $26.05 \& 24.53,24.6 \& 23.9,50.6 \& 51.5$ and $253.4 \& 265.4$ for Sharm El Sheikh city respectively, and this agrees with the pattern reviewed based on world geographic and climatic condition.
\end{abstract}

Keywords

Showalter Indices, TT Indices, K-Indices, SWEAT Indices, Radiosond, Temperature and Dew Point

\section{Introduction}

Siting of hazardous facilities such as Nuclear Power Plants requires the investigation of the meteorological and

How to cite this paper: Ahmed, O.S. and Sadek, M.A. (2015) Meteorological Indices Approach for Prediction of Thunderstorm Probability at Two Coastal Sites in Egypt. Atmospheric and Climate Sciences, 5, 219-227.

http://dx.doi.org/10.4236/acs.2015.53016 
climatological characteristics of the site region to derive extreme values of the meteorological variables to be considered in the design for safety purposes. Meteorological aspects of external hazards to be considered include extreme values of meteorological parameters as well as rarely occurring hazardous meteorological phenomena [1] [2]. The important meteorological characteristics of concern include wind, precipitation, snow, temperature, storm surges [3] [4] and rare meteorological phenomena such as lightning, tornadoes, tropical cyclones.

Lightning is a visible electrical discharge most commonly produced in thunderstorms. Lightning transients exhibit extremely high voltages, currents and current rise rates. Lightning is a significant cause of interruptions or damage in almost every electrical or electronic system that is exposed to thunderstorms, [5]. Damage is usually categorized as either direct or induced (indirect). The extreme electric field created under certain circumstances produces point discharges and can cause breakdown (a conductive path) in all but the most robust of insulators. Once a path has been established for the return stroke, currents of tens to hundreds of kiloamperes flow. It should be noted that lightning is an unpredictable transient phenomenon with characteristics that vary widely from flash to flash and whose measurement is difficult. The hazard assessment for lightning should result in an estimated annual frequency of exceedance for lightning strike for the planned nuclear power plant.

The present study devoted to predict the probability occurring thunderstorms across the North and East coasts of Egypt. Four atmospheric stability indexes are measured for that. These indexes are: K-indics, the Showalter, total totals and the SWEAT [6]. These indexes combine important meteorological parameters of concern to thunderstorms production, to determine its relative probability. Two Egyptian coastal cities have been chosen for the investigation, one on the Northern Mediteranean Sea and the other on Red Sea; El Sallum and Sharm El Sheikh, respectively.

\section{Location and climate of the Study Area}

The investigated area comprises two coastal cities in Egypt; Sham El Sheikh and El Sallum. Sharm El Sheikh city is situated on the coastal strip along the Red Sea, which includes the smaller coastal towns of Dahab and Nuweiba as well as the mountainous interior, Saint Catherine's Monastery and Mount Sinai. Nowadays it is a major touristic hotspot and resort city in Egypt [7]. And Sallum city is on the other hand situated on the Egyptian Mediterranean northwest Coast, along the border with Libya [8], as shown in Figure 1.

Table 1 and Table 2 [9] [10], show indicate mean values of the major meteoric conditions of several stations including that are concerned in the studied two cities; Sham El Sheikh and El Sallum.

\section{Methodology}

The atmospheric stability and the thunderstorm vulnerability have been examined in two coastal cities in Egypt; El Sallum at the northwest coast and Shrm El Sheikh at the Red Sea Four meteorological indexes; Showalter Index (SI) ,[11] (Total Totals Index (TT), K-index, and Severe Weather SWEAT, have been calculated and functioned for that purpose. Radio soundings [12] are used to obtain vertical profiles of thermodynamic (pressure,

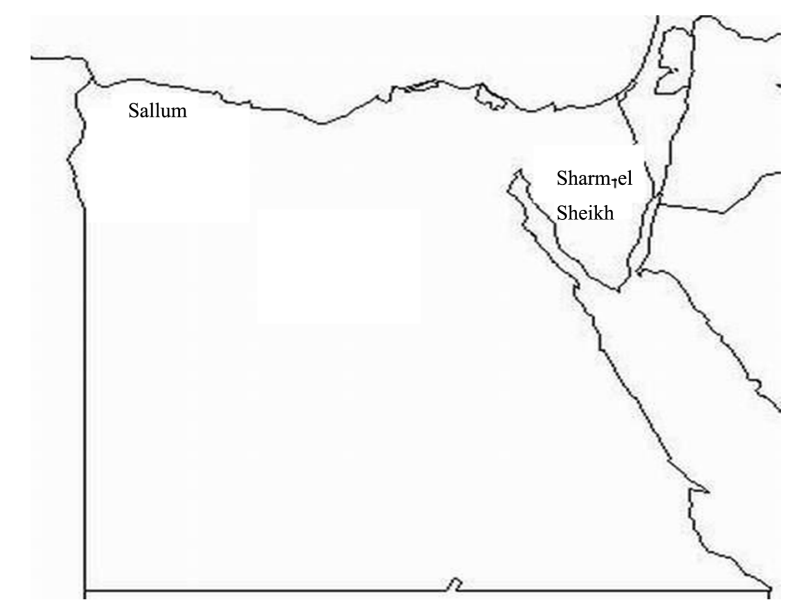

Figure 1. Map of the study area. 
Table 1. Mean monthly and annual wind speed (m/s) and its direction (at a height $10 \mathrm{~m})$.

\begin{tabular}{|c|c|c|c|c|c|c|c|c|c|c|c|c|c|c|}
\hline \multirow{2}{*}{ Station } & \multicolumn{12}{|c|}{ Month } & \multirow{2}{*}{$\begin{array}{l}\text { Annual } \\
\text { Mean }\end{array}$} & \multirow{2}{*}{$\begin{array}{c}\text { Wind } \\
\text { Direction }\end{array}$} \\
\hline & Jan. & Feb. & Mar. & Apr. & May. & Jun. & Jul. & Aug. & Sep. & Oct. & Nov. & Dec. & & \\
\hline Sallum & 5.4 & 4.8 & 5.2 & 4.3 & 3.6 & 4.1 & 4.7 & 4.2 & 3.4 & 3.6 & 4.2 & 5.2 & 4.4 & $330 \mathrm{NW}$ \\
\hline Sidi Barrani & 5.6 & 5.7 & 5.9 & 5.7 & 4.7 & 4.6 & 5.2 & 4.5 & 4.0 & 4.2 & 4.6 & 5.6 & 5.0 & $330 \mathrm{NW}$ \\
\hline Mersa Matruh & 6.1 & 6.1 & 6.3 & 5.7 & 4.9 & 5.2 & 5.2 & 4.7 & 4.4 & 4.3 & 4.8 & 5.9 & 5.3 & $330 \mathrm{NW}$ \\
\hline El Dabaa & 5.5 & 5.8 & 6.1 & 5.8 & 5.1 & 6.0 & 6.0 & 5.7 & 5.0 & 4.2 & 4.5 & 5.5 & 5.4 & $330 \mathrm{NW}$ \\
\hline Dekheila & 4.5 & 4.6 & 4.9 & 4.8 & 4.3 & 4.5 & 4.6 & 4.5 & 4.2 & 3.7 & 3.8 & 4.1 & 4.4 & $360 N$ \\
\hline Alexandria & 4.4 & 4.4 & 4.6 & 4.3 & 4.0 & 4.0 & 4.4 & 4.0 & 3.7 & 3.1 & 3.4 & 4.1 & 4.0 & $330 \mathrm{NW}$ \\
\hline Balteam & 3.6 & 3.5 & 4.2 & 4.0 & 3.5 & 3.7 & 3.9 & 3.6 & 2.8 & 2.3 & 2.6 & 3.3 & 3.4 & $330 \mathrm{NW}$ \\
\hline Damietta & 2.8 & 3.1 & 3.7 & 3.6 & 3.1 & 3.1 & 2.8 & 2.5 & 2.3 & 2.5 & 2.5 & 2.9 & 2.9 & $330 \mathrm{NW}$ \\
\hline Port Said & 4.8 & 5.2 & 5.8 & 5.4 & 4.8 & 4.6 & 4.3 & 3.8 & 3.8 & 4.1 & 4.3 & 4.3 & 4.6 & $360 N$ \\
\hline El Arish & 2.5 & 2.9 & 3.0 & 2.5 & 2.4 & 2.4 & 2.3 & 2.1 & 2.2 & 2.0 & 2.1 & 2.4 & 2.4 & $330 \mathrm{NW}$ \\
\hline
\end{tabular}

Table 2. Summary of the mean annual climatic data for the Selected Weather Stations in Egypt.

\begin{tabular}{|c|c|c|c|c|c|}
\hline \multirow{2}{*}{ Weather Station } & \multicolumn{5}{|c|}{ Mean Annual Values } \\
\hline & $\mathbf{T}\left({ }^{\circ} \mathbf{C}\right)$ & $\mathrm{S}(\mathbf{k m} / \mathbf{h})$ & SH (\%) & $\mathrm{CP}(\mathrm{mm})$ & RH (\%) \\
\hline Damietta & 21.84 & 13.56 & 88.76 & 220 & 66.81 \\
\hline Alexandria & 21.8 & 17.22 & 88.78 & 232 & 64.69 \\
\hline Port Said & 21.66 & 13.83 & 89.19 & 154 & 65.53 \\
\hline Marsa Matruh & 21.27 & 18.15 & 89.12 & 119.4 & 63.09 \\
\hline Ismailia & 22.2 & 8.97 & 87.91 & 37.5 & 54.31 \\
\hline Mansura & 22.45 & 6.77 & 81.29 & 101.6 & 62.19 \\
\hline Tanta & 21.88 & 8.38 & 84.99 & 95.3 & 59.39 \\
\hline Banha & 23.07 & 8.27 & 87.15 & 73.7 & 54.83 \\
\hline Cairo & 23.48 & 10.3 & 89.97 & 69.9 & 48.41 \\
\hline Siwa & 22.16 & 13.3 & 92.3 & 10.2 & 39.99 \\
\hline Beni Suef & 23.35 & 10.23 & 93.13 & 29.2 & 41.71 \\
\hline Sharm El Sheikh & 25.16 & 13.37 & 95.63 & 60.3 & 45.16 \\
\hline Safaga & 24.35 & 13.84 & 95.67 & 45.7 & 45.74 \\
\hline Qena & 23.1 & 8.41 & 95.67 & 34.9 & 33.11 \\
\hline Luxor & 23.42 & 7.74 & 95.69 & 33 & 33.19 \\
\hline Aswan & 24.4 & 8.59 & 96.09 & 9.5 & 27.98 \\
\hline
\end{tabular}

Where: T: mean annual air Temperature $\left({ }^{\circ} \mathrm{C}\right) \mathrm{S}$ : mean annual wind speed $(\mathrm{km} / \mathrm{h}) \mathrm{SH}$ : mean annual sun shine (\%) CP: mean annual cumulative precipitation (mm) RH: mean annual relative humidity (\%).

temperature and humidity) and dynamic (horizontal winds) variables, which have been collected from National Ocean Atmospheric Administration (NOAA) [13] for 10 years from 1989-2003 for Sallum and Sharm Sheikh. These are used for the analysis of the four indices that are described as follow:

Showalter Indices (SI) [11] (This is an indices used to determine the stability of the lower half of the troposphere. An air parcel is lifted from an initial position at $850 \mathrm{mb}$ where localized low level influences are greatly 
reduced. It is lifted dry adiabatically to its LCL and then pseudo-adiabatically to $500 \mathrm{mb}$. The environmental temperature is then subtracted from the parcel temperature to obtain the value of the Showalter index. The risk of severe weather activity is defined as follows: The index is the difference between lifted parcel temperature $\left(T_{\text {lift }}\right)$ and the environmental temperature $\left(T_{\text {env }}\right)$ at $500 \mathrm{mb}$ :

$$
S I=T_{\text {env }}-T_{\text {lift }}
$$

When $S I$ is negative, that is, the lifted temperature is warmer than the environment, the parcel is unstable.

\section{Total Totals Indices (TT)}

The Total Totals indices is a simple index derived from the temperature lapse rate between $850 \mathrm{mb}$ and 500 $\mathrm{mb}$ and moisture content at $850 \mathrm{mpse}$ rate between $850 \mathrm{mb}$ and $500 \mathrm{mb}$ and moisture content at $850 \mathrm{mb}$. It is defined as follows [14] [15]:

$$
T T=T_{850}+T d_{850}-2 T_{500}
$$

where $T_{850}$ and $T d_{850}$ are the temperature and dew point temperature respectively at the $850 \mathrm{hPa}$ level, $T_{500}$ is the temperature at the $500 \mathrm{hPa}$ level.

\subsection{K-Indices}

From Wikipedia, the free encyclopedia, K-Indices in meteorology is a measure of the thunderstorm potential based on vertical temperature lapse rate, moisture content of the lower atmosphere, and the vertical extent of the moist layer. The index is derived arithmetically: The $K$ indices is similar to Total Totals index except that it takes into account moist air at $700 \mathrm{mb}$ contributing to air mass thunderstorm development. The $K$ index is defined as follows [14] [16]:

$$
K=T_{850}-T_{500}+T d_{850}-\left(T_{700}-T d_{700}\right)
$$

where $T_{700} \& T d_{700}$ are the temperature and the dew point temperature respectively at the $700 \mathrm{hPa}$ level, $T_{500}$ is the temperature at the $500 \mathrm{hPa}$ level.

\subsection{SWEAT (Severe Weather Threat Indices) Indices}

This is an United States Air Force indices that takes into account thermal instability, low level moisture content, vertical wind shear and horizontal wind speeds. The risk of severe weather activity is defined as follows [15] [17]:

$$
\text { SWEAT }=12 T d_{850}+20(T T-49)+2 f_{850}+f_{500}+125\left(\sin \left[d_{500}-d_{850}\right]+0.2\right)
$$

where $\mathrm{f}_{850}$ is the wind speed at $850 \mathrm{hPa}$ in knots, $\mathrm{f}_{500}$ is the wind speed at $500 \mathrm{hPa}$ in knots, $\mathrm{d}_{850}$ is the wind direction at $850 \mathrm{hPa}, \mathrm{d}_{500}$ is the wind direction at $500 \mathrm{hPa}$

\section{Results and Discussion}

The average values of the four indices chosen to infer the probability of occurrence of thunderstorm in El Sallum and Sharm El Sheikh cities at January and February for the years, 1989-2003 are indicated in Table 3 and Table 4. The indicated values of El Sallum city vary in the range from 17.8 to 23.40 and 16.19 to $20.3 \&-22.34$ to -3.22 and -20.52 to $-2.54 \& 20.15$ to 31.5 and 20.53 to 33.06 and 79.54 to $113.02 \& 77.05$ to 113.02 for SI \& K \& TT and SWEAT indices respectively. On the other hand, Sharm El Sheikh city shows values varying in the range from 16.5 to 19.53 and 15.62 to $18.51 \&-14.57$ to -1.77 and -15.88 to $2.65 \& 28.42$ to 35.27 and 27.53 to 36.79 and 81.28 to $112.65 \& 79.98$ to 125.89 respectively.

The columnar diagrams, Figures 2-7 illustrate the variability and comparability of the indicated values. The range of variation is narrower in ElSallum than Sharm ElSheikh indicating a more homogeneous and stable meteoric condition.

The following categories of SI, TT, K and SW describe the probability of thunderstorms hazard and the risk associated with it [17]

SI values $>3$ No significant activity

SI values $1<\mathrm{SI}<3$ Showers possible with other source of lift

SI values $-3<$ SI $<-2$ Thunderstorms more probable (possibly strong) 


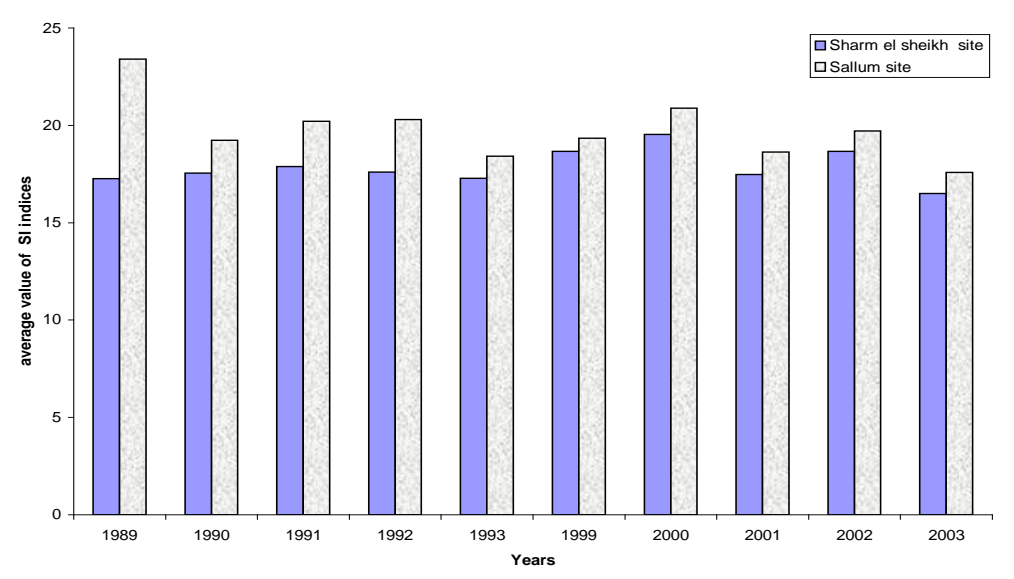

Figure 2. Average value of SI indices at January month.

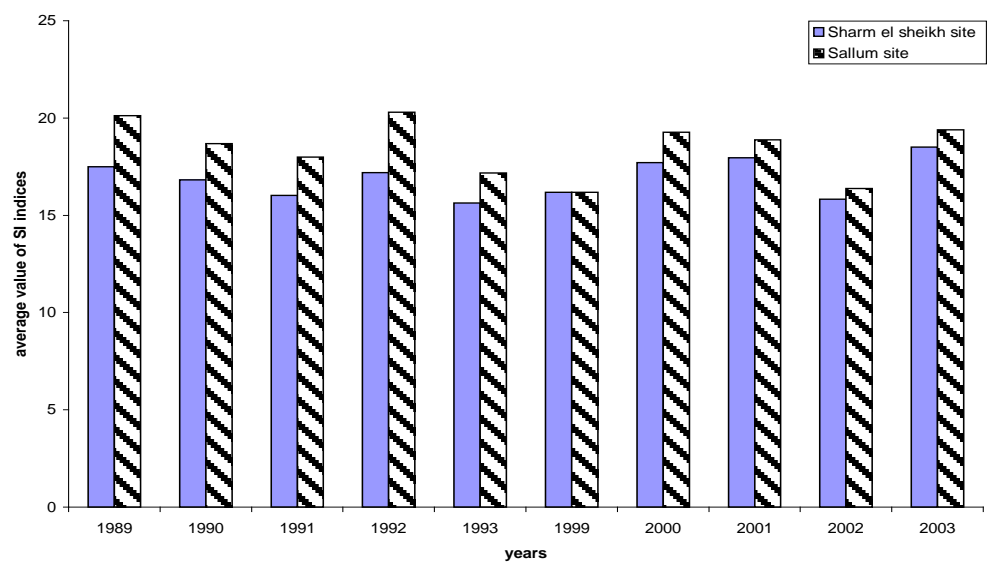

Figure 3. Average value of SI indices at February month.

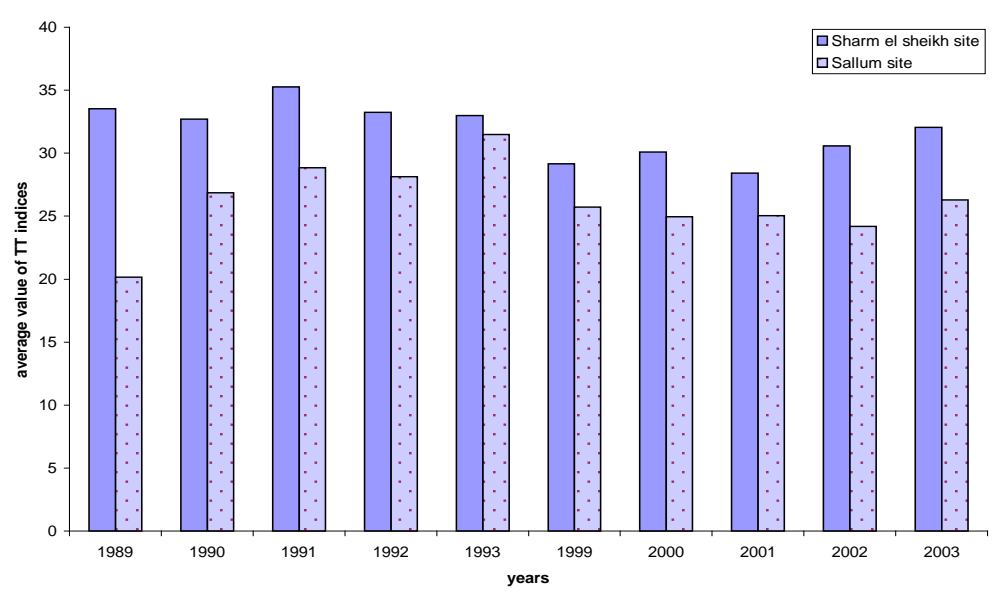

Figure 4. Average value of TT indices at January month.

SI values $-2<$ SI $<1$ Thunderstorms possible (generally weak)

SI values $-6<$ SI $<-4$ Strong or severe thunderstorms possible SI values SI $<-6$ Any thunderstorms likely to be strong or severe TT values 44 - 45 Isolated moderate thunderstorms

TT values 46 - 47 Scattered moderate/few heavy thunderstorms 
Table 3. Average value for different indics at different year for Sallum city.

\begin{tabular}{ccccccccc}
\hline & \multicolumn{2}{c}{ SI INDICS } & \multicolumn{2}{c}{ K INDICS } & \multicolumn{2}{c}{ TT INDICS } & \multicolumn{2}{c}{ SWEAT INDICS } \\
\hline & January & February & January & February & January & February & January & February \\
\hline 1989 & 23.40 & 20.11 & -22.34 & -17.57 & 20.15 & 24.96 & 99.85 & 90.12 \\
1990 & 19.24 & 18.68 & -8.35 & -6.16 & 26.87 & 33.06 & 94.87 & 77.05 \\
1991 & 20.21 & 17.99 & -7.81 & -8.55 & 28.85 & 28.64 & 84.41 & 96.12 \\
1992 & 20.30 & 20.30 & -12.70 & -12.70 & 28.13 & 28.13 & 113.02 & 113.02 \\
1993 & 18.42 & 17.18 & -3.22 & -2.54 & 31.50 & 32.65 & 79.54 & 104.39 \\
1999 & 19.34 & 16.19 & -12.01 & -13.30 & 25.73 & 23.79 & 85.53 & 98.52 \\
2000 & 20.89 & 19.27 & -15.18 & -17.15 & 24.95 & 27.07 & 101.56 & 108.14 \\
2001 & 18.63 & 18.88 & -20.31 & -20.51 & 25.05 & 24.19 & 86.49 & 112.57 \\
2002 & 19.71 & 16.37 & -18.81 & -14.03 & 24.20 & 27.07 & 81.80 & 90.34 \\
2003 & 17.58 & 19.39 & -15.56 & -18.81 & 26.29 & 20.53 & 102.94 & 95.94 \\
\hline
\end{tabular}

Table 4. Average value for different indics at different year for Sharm El Sheihk city.

\begin{tabular}{|c|c|c|c|c|c|c|c|c|}
\hline & \multicolumn{2}{|c|}{ SI INDICS } & \multicolumn{2}{|c|}{ K INDICS } & \multicolumn{2}{|c|}{ TT INDICS } & \multicolumn{2}{|c|}{ SWEAT INDICS } \\
\hline & January & February & January & February & January & February & January & February \\
\hline 1989 & 17.27 & 17.49 & -4.24 & -9.84 & 33.54 & 30.45 & 98.19 & 92.14 \\
\hline 1990 & 17.54 & 16.82 & -4.21 & 0.17 & 32.71 & 36.79 & 97.80 & 115.33 \\
\hline 1991 & 17.89 & 16.03 & -1.77 & -2.10 & 35.27 & 34.93 & 112.65 & 99.59 \\
\hline 1992 & 17.60 & 17.19 & -5.06 & -2.59 & 33.25 & 36.47 & 94.05 & 125.89 \\
\hline 1993 & 17.27 & 15.62 & -2.11 & 2.65 & 32.98 & 36.64 & 96.23 & 106.66 \\
\hline 1999 & 18.67 & 16.18 & -9.75 & -10.39 & 29.17 & 27.92 & 107.81 & 96.54 \\
\hline 2000 & 19.53 & 17.72 & -7.37 & -12.89 & 30.10 & 31.60 & 81.28 & 83.03 \\
\hline 2001 & 17.48 & 17.96 & -13.27 & -11.75 & 28.42 & 29.06 & 84.58 & 90.09 \\
\hline 2002 & 18.67 & 15.83 & -14.57 & -15.88 & 30.58 & 31.76 & 85.73 & 82.75 \\
\hline 2003 & 16.50 & 18.51 & -8.57 & -11.97 & 32.05 & 27.53 & 90.44 & 79.98 \\
\hline
\end{tabular}

TT values 48 - 49 Scattered moderate/few heavy/isolated severe thunderstorms

TT values 50 - 51 Scattered heavy/few severe thunderstorms and isolated tornadoes

TT values 52 - 55 Scattered to numerous heavy/few to scattered severe thunderstorm/few tornadoes

TT values $>55$ Numerous heavy/scattered severe thunderstorms and scattered tornadoes

$\mathrm{K}$ value Less than $15=0 \%$ Probability of Thunderstorm

$\mathrm{K}$ value 15 to $20=20 \%$ Probability of Thunderstorm

K value 21 to $25=20$ to $40 \%$ Probability of Thunderstorm

K value 26 to $30=40$ to $60 \%$ Probability of Thunderstorm

K value 31 to $35=60$ to $80 \%$ Probability of Thunderstorm

K value 36 to $40=80$ to $90 \%$ Probability of Thunderstorm

$\mathrm{K}$ value Above $40=$ near $100 \%$ Probability of Thunderstorm

SW values $<300$ No severe storms expected

SW values $>300$ values and SW values $<400$ Possible severe thunderstorms

SW values $>400$ Severe thunderstorms likely and possible tornadoes 


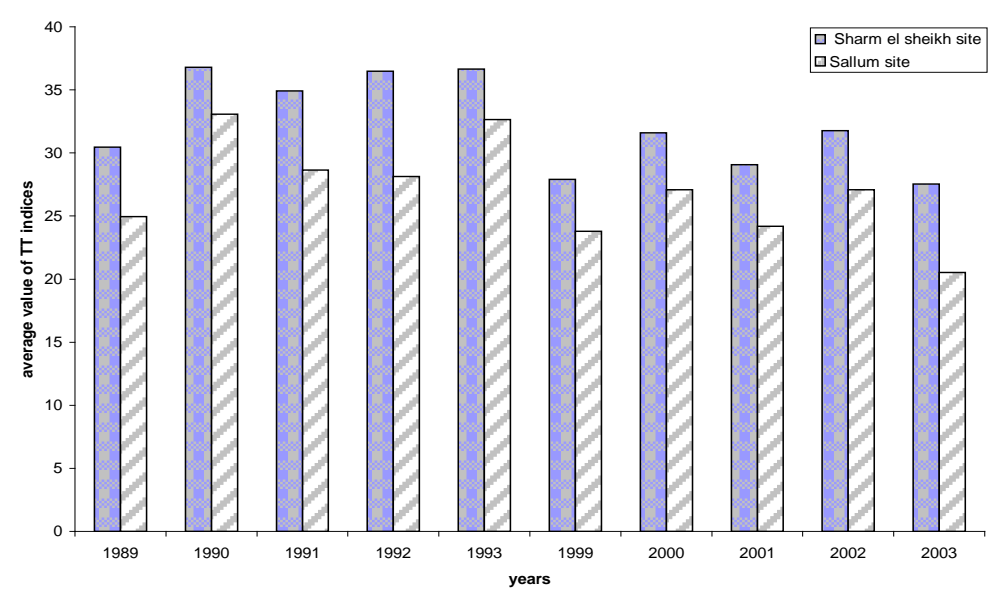

Figure 5. Average value of TT indices at February month.

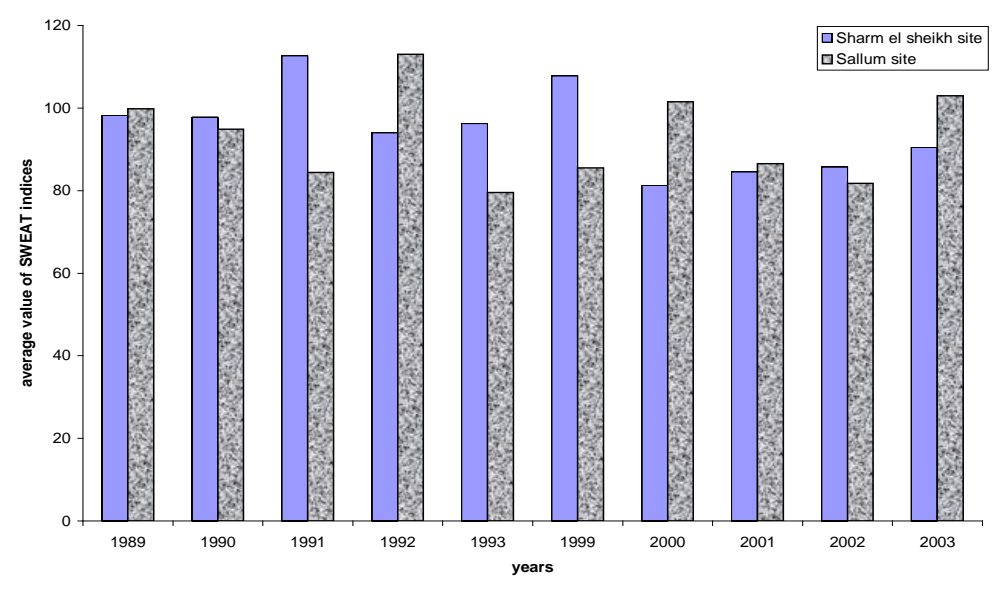

Figure 6. Average value of SWEAT indices at January month.

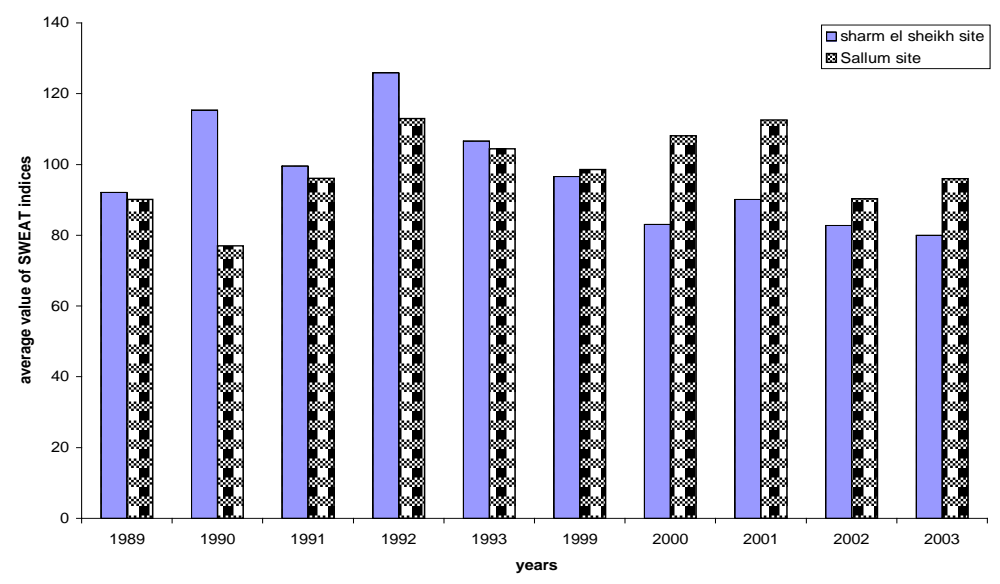

Figure 7. Average value of SWEAT indices at February month.

Comparing the values calculated for the four indexes with the indicated categories a considerable comparability exists. The probability of thunderstorm occurrence in the two examined cities, El Sallum and Sharm El Sheikh is low to moderate (in the range of $20 \%$ ). Sharm El Sheikh is little more vulnerable than El Sallum to thunderstorm but still categorized with it. This results are highly compatible with the indicated geographical distribution of thunderstorm in the world, Figure 8, this could validate the use of the four indexes for referring the 


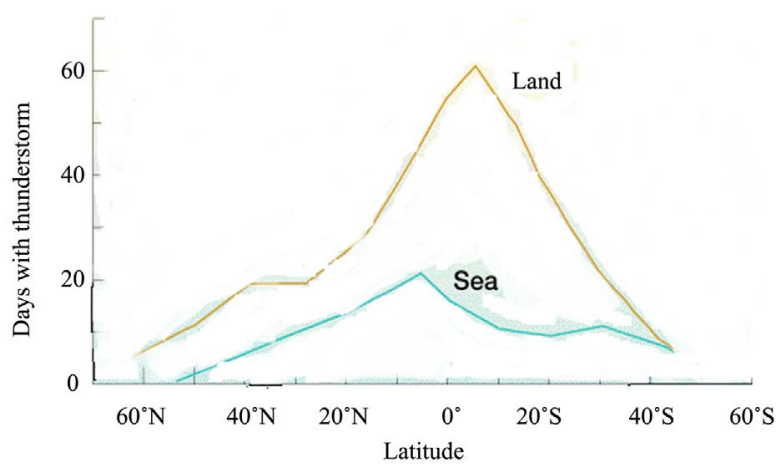

Figure 8. Days with thunderstorm vs latitude.

thunderstorm potentiality for a given locality.

\section{Conclusion}

The current investigation has been conducted to satisfy one of the required information for safe siting of hazardous facilities such as Nuclear Power Plants. The thunderstorm probability of occurrence has been determined for two El Sallum and Sharm El Sheikh cities in the Egyptian coasts. The four meteoric stability indexes employed for the study proved that likelihood of thunderstorm occurrence is low to moderate (in the range of $20 \%$ ). An agreement exists with reviewed work on world distribution of thunderstorm reflecting the usability of these indexes as predictors in most cases.

\section{References}

[1] IAEA (2011) Safety Aspects in Siting for Nuclear Installations, Draft Safety Guide, DS433. IAEA, Vienna.

[2] International Atomic Energy (1980) Atmospheric Dispersion in Nuclear Power Plant Siting. A Series No. 50-SG-S3, IAEA, Vienna.

[3] Huntrieser, H., Schiesser, H.H., Schmid, W. and Waldvogel, A. (1997) Comparison of Traditional and Newly Developed Thunderstorm Indices for Switzerland. Weather and Forecasting, 12, 108-125. http://dx.doi.org/10.1175/1520-0434(1997)012<0108:COTAND>2.0.CO;2

[4] Haklander, A.J. and Van Delden, A. (2003) Thunderstorm Predictors and Their Forecast Skill for the Netherlands. Atmospheric Research, 67-68, 273-299.

[5] Adegboyega, G.A. and Odeyemi, K.O. (2012) Assessment of Areas That Are Prone to Thunderstorm Activities in the Northeast Zone of Nigeria. Journal of Academic and Applied Studies (JAAS), 2, 1-7.

[6] Gottlieb, R.J. (2009) Analysis of Stability Indices for Severe Thunderstorms in the Northeastern United States. Honors Thesis, College of Agriculture and Life Sciences, Physical Sciences of Cornell University, Ithaca, NY.

[7] http://en.wikipedia.org/wiki/Sharm_el-Sheikh

[8] http://en.wikipedia.org/wiki/Sallum

[9] Elshaeb, M.A., El-Badawy, S.M. and Shawaly, El-S.A. (2014) Development and Impact of the Egyptian Climatic Conditions on Flexible Pavement Performance. American Journal of Civil Engineering and Architecture, 2, 115-121.

[10] Shata, A.S.A. (2008) Theoretical Investigation and Mathematical Modelling of a Wind Energy System Case Study for Mediterranean and Red Sea. Ph.D. Thesis, Technische Universität Berlin, Berlin.

[11] Showalter, A.K. (1953) A Stability Indices for Thunderstorm Forecasting. Bulletin of the American Meteorological Society, 34, 250-252.

[12] Jayakrishnan, P.R. and Babu, C.A. (2014) Assessment of Convective Activity Using Stability Indices as Inferred from Radiosonde and MODIS Data. Atmospheric and Climate Sciences, 4, 122-130. http://dx.doi.org/10.4236/acs.2014.41014

[13] www.arl.noaa.gov/ready

[14] Bluestein, H. (1993) Synoptic-Dynamic Meteorology in Midlatitudes: Vol II Observations and Theory of Weather Systems. Oxford University Press, New York, 594 p.

[15] Miller, R.C. (1972) Notes on Analysis and Severe Storm Forecasting Procedures of the Air Force Global Weather 
Central. Tech. Rept. 200(R), Headquarters, Air Weather Service, USAF, 190 p.

[16] George, J.J. (1960) Weather Forecasting for Aeronautics. Academic Press, Waltham, MA, 673 p.

[17] Djuric, D. (1994) Weather Analysis. Prentice-Hall Inc., 304 p. 